Article

\title{
Persuasive Normative Messages: The Influence of Injunctive and Personal Norms on Using Free Plastic Bags
}

\section{Judith I.M. de Groot ${ }^{1{ }^{*},}$, Wokje Abrahamse ${ }^{2}$ and Kayleigh Jones ${ }^{1}$}

1 School of Design, Engineering and Computing, Bournemouth University, Talbot Campus, Poole House, Poole, BH12 5BB, UK; E-Mail: kayleighjones1990@live.co.uk

2 Department of Psychology, University of Victoria, PO Box 3050, Victoria, BC, V8W 3P5, Canada; E-Mail: wokjea@uvic.ca

* Author to whom correspondence should be addressed; E-Mail: jdgroot@bournemouth.ac.uk; Tel.: +44-0-1202-961557; Fax: +44-0-1202-962736.

Received: 17 January 2013; in revised form: 11 April 2013 / Accepted: 16 April 2013 / Published: 29 April 2013

\begin{abstract}
In this exploratory field-study, we examined how normative messages (i.e., activating an injunctive norm, personal norm, or both) could encourage shoppers to use fewer free plastic bags for their shopping in addition to the supermarket's standard environmental message aimed at reducing plastic bags. In a one-way subjects-design $(N=200)$ at a local supermarket, we showed that shoppers used significantly fewer free plastic bags in the injunctive, personal and combined normative message condition than in the condition where only an environmental message was present. The combined normative message did result in the smallest uptake of free plastic bags compared to the injunctive and personal normative-only message, although these differences were not significant. Our findings imply that re-wording the supermarket's environmental message by including normative information could be a promising way to reduce the use of free plastic bags, which will ultimately benefit the environment.
\end{abstract}

Keywords: normative influence; norms; injunctive norms; personal norms; message framing; sustainable behavior 


\section{Introduction}

The production of plastic bags uses natural resources such as oil, and releases carbon emissions into the atmosphere. Plastic bags account for a large part of our waste in landfills, and they are one of the most frequently discarded items of litter in forests and on beaches. A large number of plastic bags end up in seas and oceans and as a result about 1 billion seabirds and mammals die every year because they mistake the bags for food. In addition, plastic bags can take up to 1,000 years to decompose [1]. So with over 8 billion plastic bags used in the UK alone every year [2], plastic bags are a very real threat to the environment. This threat is well recognized by conservation professionals: "Plastic bags exceed what you would anticipate would be their pollution impact, because they're so much more mobile than other types of litter," (Samantha Fanshawe, Director of Conservation, UK Marine Conservation Society, cited in [3]). It is therefore important to try and reduce the amount of plastic bags that are used on a day to day basis. The present study explores how shops can reduce the use of free plastic bags by normative message framing.

\subsection{Normative Influence and Pro-Environmental Behavior}

Pro-environmental behaviors, such as decreasing the use of plastic bags, can be defined as behaviors which benefit the environment by changing the availability of materials or energy from the environment or altering the structure and dynamics of ecosystems in a positive way [4,5]. Acting pro-environmentally entails that other people or the environment may benefit, whereas often, no direct individual benefits are received by engaging in these behaviors. Pro-environmental behavior often implies acting on a normative basis, that is, acting on considerations of what is the right or wrong thing to do for the community and the environment according to oneself and important others [6,7]. A lot of models focus on such normative considerations by including social or personal norms for explaining pro-environmental behaviors (e.g., [8-13]). Hence, a potentially effective way to decrease the use of free plastic bags in shops is the use of persuasive normative messages.

\subsection{Persuasive Normative Messages: Using Social Norms to Promote Pro-Environmental Behavior}

Social norms are customary rules of behavior that guide our interactions with others [14]; they are thought to be beliefs about what are common and accepted behaviors for specific situations [15]. Research on social norms and pro-environmental behavior shows that social norms can be an important determinant for explaining these actions [16-20]: a stronger social norm is more strongly related to behavior that is in congruence with this norm.

The focus theory of normative conduct [21,22] states that social norms can mobilize decision making processes, especially when they are made salient, or focal, in a specific situation (see also [23]). One way to increase the saliency of norms is by persuasive normative messages [24]. For example, Goldstein et al. [25] worked with a local hotel on a program to encourage guests to reuse towels to save on water and electricity. Different messages urging guests to reuse their towels were used. The findings indicated that an environmental message which made a descriptive social norm salient (i.e., "Join your fellow citizens in helping to save the environment") was more successful in motivating guests to reuse their towels compared to a standard environmental message. This persuasive normative 
message encouraged $44 \%$ of guests to reuse their towels, as opposed to only $31 \%$ when the cards used a generic environmental protection message (Study 1). Specifying that $75 \%$ of the guests who had stayed in the same room had reused their towels further increased towel reuse to $49 \%$.

The studies that have focused on normative message framing and pro-environmental behavior have mostly focused on reducing littering [22], reusing towels (e.g., [24-26]) or reducing energy consumption (e.g., [27,28]). As far as we are aware, there are no studies that have examined the effect of normative message framing on the use of free plastic bags in a supermarket setting. As such, this study aims to examine whether the effectiveness of normative message framing can be replicated in the context of this different type of pro-environmental behavior and field-study behavioral context (i.e., a large supermarket, open 24/7, with a focus on reducing the use of free plastic bags).

Cialdini et al. [21] state that there are two distinct types of social norms; that is, descriptive and injunctive social norms. Descriptive social norms refer to what is commonly done, for example: " $80 \%$ of people in the UK reuse their plastic bags on a regular basis". Injunctive social norms refer to what is commonly approved or disapproved of, such as " $80 \%$ of people in the UK believe (i.e., approve of) that reusing plastic bags is important".

Both descriptive and injunctive social norms can be used in persuasive normative messages to encourage pro-environmental behaviors (e.g., [24-29]). The study of Jacobson et al. [30] showed that there was no significant difference between an injunctive or descriptive normative message on prosocial behavior. They showed that both the injunctive ("most students indicated that participants should be willing to stay for the full hour and complete extra surveys") and the descriptive ("most students have chosen to stay for the full hour and complete extra surveys") normative message were equally effective in terms of helping behavior among students. That is, when students were asked to help the researcher to complete extra surveys, both messages resulted in a similar number of students offering to help out, indicating an equal strength of both messages when influencing behavior.

However, there is some evidence indicating that focusing on descriptive norms is ineffective in promoting pro-environmental behaviors in situations characterized by high levels of undesirable conduct [26,31]; and, in some instances can even result in the inhibition of the influence of salient injunctive norms (in favor of the desired behavior) that are in place [32,33]. For example, Cialdini et al. [26] showed that a strong injunctive normative message ("Please don't remove the petrified wood from the park") resulted in less theft of petrified wood in a nature reserve (1.67\%) than a message emphasizing the descriptive norm about the severity of the problem ("Many visitors have removed the petrified wood from the park, changing the state of the Petrified Forest") (7.92\%). Only $2.92 \%$ of the visitors stole petrified wood when no sign was present, indicating that emphasizing an undesirable descriptive norm can even result in a boomerang-effect. Therefore, scholars have emphasized the importance of focusing on the injunctive norm instead of the descriptive norm when most people are showing the undesired behavior [24,26,31,34,35]. According to the supermarket's figures in our study, $88 \%$ of the customers only use free plastic bags rather than recycled bags. So, a large majority of customers do not show the desired behavior. This study therefore examines whether behavior change can be encouraged by means of normative message framing with a focus on the injunctive norm, rather than the descriptive norm. 


\subsection{Persuasive Normative Messages: Using Personal Norms to Promote Pro-Environmental Behavior}

An additional factor which may be used in persuasive normative messages to encourage pro-environmental behaviors is personal norms. Personal norms refer to an individual's belief about their moral obligation to engage in a specific behavior [36]. Thus, personal norms are specific standards for one's own behavior instead of one's beliefs about what other people think or do [37]. Personal norms have been shown to strongly predict a diversity of pro-environmental intentions and behaviors, including (reducing) car use (e.g., [38,39]), buying environmentally-friendly products [40-42], and the adoption of alternative fuelled vehicles [43]. These studies indicate that the stronger one's personal norm to act pro-environmentally, the more someone is inclined to make pro-environmental choices and act pro-environmentally.

As proposed in the focus theory of normative conduct [21], we assume that personal norms should also be made salient to be able to exert an effect on behavior. This assumption is also emphasized by the norm activation model [44], which proposes that behavior is guided mainly by an activated personal norm. Although there have been various empirical studies that focused on how social norms can be framed in messages to change behavior, personal norms have hardly been used in research related to persuasive normative messages. Therefore, we will also explore how personal normative messages can potentially be used to promote reducing the use of plastic bags in the current study.

An example of how to activate someone's personal norms by persuasive normative messages is provided by the work of Bolderdijk et al. $[45,46]$. They made personal norms salient by explicitly linking personal pronouns to a moral message. It is assumed that all people have to some extent personal norms in favor of the environment. Personal pronouns allow people to link these beliefs about what would actually be "the right thing to do" to their moral self-concept hereby activating these internalized norms, and, consequently, that person may act more in line with these norms. Bolderdijk and colleagues [46] showed in a field-experimental observational study on free tire checks at a gas station that a moral appeal on a sign placed at a gas station ("Do you care for the environment? Get a free tire check") resulted in significantly more coupon uptakes for free tire checks than the economic ("Do you care about your finances? Get a free tire check") or control appeal ("Get a free tire check") when personal pronouns were linked with the moral message (Study 3). In other words, linking moral messages to one's self-concept will activate or make salient an already existing personal norm towards the pro-environmental behavior. Therefore, we will use this strategy to activate one's personal norms towards reusing plastic bags (and consequently reduce the use of free plastic bags).

To conclude, social as well as personal norms seem to be effective triggers for encouraging pro-environmental behaviors. The present study will use normative persuasive messages to make social and personal norms salient. First, we will try to replicate the aforementioned field studies in another pro-environmental behavioral domain (i.e., reducing the uptake of free plastic bags) to see whether indeed an injunctive normative message will decrease the uptake. Based on the literature review above, we expect that:

H1-Customers will use significantly fewer free plastic bags when an injunctive normative message in favor of reusing bags is made salient compared to the environmental-only condition in which only 'caring for the environment' is made salient. 
Second, this study is one of the first to further explore how personal norms can be activated by normative persuasive messages. Based on the literature on the relationships between personal norms and pro-environmental behaviors (e.g., [38-43]), and the focus theory of normative conduct [21], we hypothesize that:

H2 - Customers will use significantly fewer free plastic bags when a personal normative message in favor of reusing bags (i.e., linking personal pronouns to the message of helping the environment) is made salient compared to the environmental-only condition.

\subsection{Persuasive Normative Messages: Combined Injunctive and Personal Normative Messages}

Research on normative message framing assumes that it is important that normative messages should be aligned to exert the strongest influence on environmental behaviors [15,24]. However, there is a lack of empirical studies that have investigated the relative influence of aligned normative messages, especially in relation to combining an injunctive with a personal normative message. Our study further seeks to identify whether combined normative messages (i.e., making both social injunctive norms and personal norms salient) will be more powerful in decreasing the use of plastic bags in a local supermarket compared to the persuasive normative messages individually.

There is some support that normative messages exert a stronger influence on behavior when norms are aligned. For example, in an intervention study on the effect of normative messages and the reuse of bath towels among hotel guests, Schultz et al. [24] found that $62 \%$ of guests who received an aligned message that made the desired behavior (i.e., reusing your towel) salient by a combination of a descriptive and injunctive normative message reused their bath towel at least once during their stay. This percentage was significantly higher than the $57 \%$ of the hotel guests that reused their towels in the control condition, in which the guests only received a message about the environmental benefits of reusing towels.

In another study, Smith and Louis [47] showed an interaction effect between the injunctive and descriptive norms: the impact of a salient injunctive norm to sign a petition against full-fee places for domestic undergraduate students was stronger when the descriptive norm to support this signing was salient as well. Finally, in three large scale surveys, Thøgersen [48] consistently found that the effect of the injunctive and descriptive norms combined were stronger than their additive effects for explaining a diversity of self-reported pro-environmental behaviors. In other words, it seems that if both injunctive and descriptive normative messages are supportive towards behavior, their combined effect may be further facilitating this behavior (see also [49]). Based on these studies, we would expect that a combined injunctive and personal normative message in favor of the desired behavior may also result in the least use of free plastic bags. However, our study focuses on a combination of injunctive and personal normative messages rather than descriptive and injunctive normative messages. Descriptive norms are different from personal norms as they tap into different underlying motivational aspects (see e.g., [50]). Thus, could the sum of activating injunctive and personal norms combined be more than their individual contribution on behavior change?

Based on theories in social psychology, we would expect so. For example, psychologists [50,51] have suggested that social norms are processed in a different way than personal norms. They argue that social norms influence behavior on a more subconscious level because they tend to be mainly 
associated with affective beliefs [50]; while personal norms can motivate someone to act in a more conscious way as well because they tend to be associated more strongly with cognitive beliefs [50]. Thus, a message that activates an injunctive and a personal norm may ultimately result in influencing more people because they can process the message in the way that fits them best personally. Therefore, the combination of making salient injunctive and personal norms is expected to result in the most persuasive normative message.

To the authors' knowledge, there is no research that investigates the combined effects of various types of normative messages (social norms and personal norms) on pro-environmental behavior. This study will be one of the first that explores such effects. Based on the assumption that aligned messages assert the strongest influence on one's behavior (e.g., $[15,24,47]$ ) and a combined message can activate both norms depending on which norm is most important for the person to act upon in first instance [49], we expect that:

H3 - Customers will use significantly fewer free plastic bags when a social and personal normative message in favor of reusing bags are both made salient compared to either of the messages alone and the environmental-only condition.

\section{Method}

\subsection{Design}

The design used in the study was a one-way between-subjects design. The supermarket was part of a large multi-national corporate organization, which uses the same national signs and messages in all shops across the UK. Consequently, we could not remove present signs and messages from the experimental setting. The independent variable (i.e., type of normative message) therefore always included the original signs of the supermarket as well. The independent variable consisted of four levels: (1) an injunctive normative message with the environmental message of the supermarket, (2) a personal normative message combined with the environmental message of the supermarket, (3) a combined injunctive and personal normative message with the environmental message of the supermarket, and, (4) the environmental message only (i.e., the messages as presently used in the supermarket). The dependent variable was the number of free plastic bags customers used when doing their shopping.

\subsection{Participants}

Participants consisted of customers shopping at a local 24/7 supermarket in Bournemouth (UK) who paid for their shopping at the till which was being observed. Every third customer was observed and recorded to make it a systematic random sample. Customers who already brought their own reusable bags were deleted from data collection, because they could not be affected by the normative messages at present. The next customer was observed instead.

Statistical power analyses to calculate an accurate sample size prior the study was not used because we did not have such statistics available yet for the specific context in which this study took place (i.e., reducing free plastic bags, with two specific types of injunctive and personal normative messages, 24/7 shop in UK context). The sample sizes were therefore estimated based on a rule of thumb 
(i.e., two to three times the amount of participants in each condition compared to a similar study that would have been conducted in a fully-controlled lab-setting). Therefore, fifty participants for each of the four conditions were observed and recorded ( $N=200 ; 59 \%$ Males).

The group that participants were shopping in was also recorded (14\% Family; $27 \%$ Couple; $59 \%$ Single). If the participants were not alone, the sex of the participant was determined by the member of the group that paid for the shopping. The size of the shopping was also reported by observing whether the participants had their shopping in a large trolley (reported as "large shopping"; 8\%), a small trolley (reported as "medium shopping"; 54\%), or a basket (reported as "small shopping"; 38\%). Unfortunately we were not allowed to randomly allocate customers to the different message conditions (e.g., changing the messages on an hourly basis; having several observation times for each condition). The management indicated this would be too distracting for the customers and members of staff. Therefore, this study should be regarded as a field-study rather than a field-experimental study.

\subsection{Pilot Study}

First, we examined what kind of message would be best for the social normative message at the supermarket. The supermarket provided current figures, which showed that on average $12 \%$ of transactions during a typical week involved reusing bags. Based on this information, we concluded that the majority of customers conducted the undesired behavior of using free plastic bags. This meant that the use of an injunctive normative message would be more appropriate than highlighting a descriptive social norm. As outlined earlier, the reasoning behind this is that injunctive norms ban or discourage the undesired behavior, whereas descriptive norms using free plastic bags would only set a standard that acts as a magnet for behaving in an undesired way [26,28].

Next, we recruited 20 customers at the supermarket to fill in a questionnaire about the reuse of shopping bags to determine the appropriate injunctive norm regarding the reuse of shopping bags and decreasing the use of free plastic bags. We assumed that the majority of shoppers would approve of reusing shopping bags instead of using free plastic bags because it is an easy behavior, which benefits the environment. The results of the questionnaire indeed confirmed this: all 20 customers believed that re-using shopping bags was at least "somewhat important" in helping the environment. This gave reason to use the injunctive norm regarding plastic bag use as a means of discouraging the use of free plastic bags (i.e., "Shoppers in this store believe that re-using shopping bags is a useful way to help the environment. Please continue to re-use your bags").

\subsection{Procedure}

The study took place at a local 24/7 supermarket. Data was recorded through observation in a naturalistic setting (the supermarket) by one and the same observer. The observer had a good view over the observed till so there were no problems encountered with counting the numbers of free plastic bags used. The observer was positioned in such a way that it was highly unlikely the customer noticed the observer. It was decided that data collection would take place over a short period of time to account for weekly customers, and to decrease the chance that the same customers would be included in the different conditions. Therefore, data collection took place over one weekend (Saturday between 8 am and $8 \mathrm{pm}$ and Sunday between 10 am and $4 \mathrm{pm}$ ) outside any specific holiday periods. The 
supermarket's manager indicated that there could be differences between weekly and weekend shoppers, but she did not observe any obvious differences between shoppers that either shopped on a Saturday or Sunday (in the morning or afternoon), hereby limiting the chance that the customers were significantly different on potentially confounding variables because of the non-randomized design.

Most well-known 24/7 supermarkets in the United Kingdom still have a policy to offer free plastic bags to customers next to offering more durable re-usable bags for a certain amount of money. The specific store where we conducted our study had this policy as well. The person behind the till always put free plastic bags in the bagging area at the till, but the customer also had the opportunity to buy re-usable bags (the cheapest "plastic" reusable bags were 10 pence apiece); this remained constant across all four conditions during the experiment. The customer did not get any help while bagging their shopping. Therefore, all customers had the opportunity to take as many free plastic bags or alternative re-usable bags as they found sufficient, and there was nobody (no "baggers") who interfered with them bagging their groceries.

Signs were placed in the supermarket, which displayed messages to make the injunctive social norms, personal norms, and combined injunctive and personal norms salient (see Figure 1). For the control condition, no signs other than the supermarket's original signs were displayed, which stated "Caring for the environment. Reuse your bags". For each of the manipulation conditions, one A1 sized sign, two A3 sized signs and six A4 sized signs were displayed alongside these original signs.

It could be argued that a normative message about re-using bags in general may not influence the use of free plastic bags specifically. However, empirical studies suggest otherwise. Apparently, using a normative message does more than just make someone focus on a specific type of behavior (e.g., re-using bags). A normative message may activate one's normative goals towards acting in desirable and appropriate ways in a situational context as a whole (see e.g., [33]). Thus, a normative message will put someone's "normative goals" in the foreground which will activate other relevant behaviors, such as decreasing the use of plastic bags, in the context as well. Furthermore, bringing reusable bags is something that is often already decided prior the shopping. What customers can do "immediately" to act upon the message is to at least use as few free plastic bags as possible, by either buying reusable bags, packing more efficiently, or just carrying (some of) their shopping without a bag. So free plastic bag use was the most robust variable on an interval level that we could take as a measure for how customers responded to the different messages.

On the first day of data collection, no additional signs were displayed to make this the environmental-only condition. Every 3rd customer was observed, and data recorded on a selected till which remained the same for the duration of the data collection. The observed till was chosen as it was a busy till and it faced a blank wall which was convenient for displaying the larger signs. Then, signs with the high injunctive normative message were put up opposite and alongside the till area that was being observed, and again every 3rd customer was observed, until data on 50 customers had been collected. The observer did not record whether the participants actually saw the sign, because it was not possible to do this unobtrusively. To correct for this, we made sure the sample sizes of each condition $(n=50)$ were large to strengthen the study's power. Thirty minutes were left between putting up signs and the beginning of new observations, as putting up the signs could draw extra attention to the signs. This procedure was then repeated for the high personal norm condition and the combined high injunctive norms and high personal norm condition. 
Figure 1. Persuasive Normative Messages.

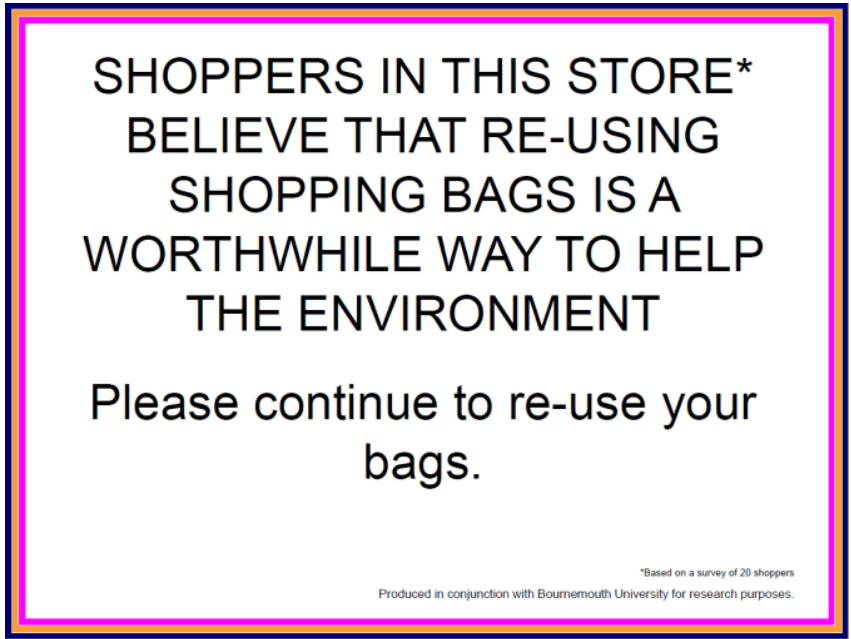

(a) Injunctive Normative Message.

\section{WE THANK YOU FOR} HELPING THE ENVIRONMENT BY CONTINUING TO REUSE YOUR BAGS.

(b) Personal Normative Message.

SHOPPERS IN THIS STORE* BELIEVE THAT RE-USING SHOPPING BAGS IS A WORTHWHILE WAY TO HELP THE ENVIRONMENT

WE THANK YOU FOR HELPING THE ENVIRONMENT BY CONTINUING TO RE-USE YOUR BAGS.

(c) Combined Normative Message.

\section{Results}

The descriptive statistics (see Table 1) suggest that on average, fewer free plastic bags were used during the experimental conditions compared to the standard environmental-only condition $(\mathrm{M}=3.12)$. 
The means of the combined condition of injunctive and personal normative messages suggest that this condition resulted in the smallest amount of plastic bag use $(M=1.86)$. And, although the mean of the injunctive normative message $(\mathrm{M}=2.04)$ was somewhat smaller than the personal normative message condition $(\mathrm{M}=2.44)$, these differences seemed rather small and the $95 \%$ C.I. overlapped largely.

Table 1. Descriptive Results for the Number of Plastic Bags Used for each Condition.

\begin{tabular}{ccccc}
\hline Condition & $\boldsymbol{M}$ & $\boldsymbol{S D}$ & $\boldsymbol{S E}$ & $\mathbf{9 5 \%} \boldsymbol{C I}$ \\
\hline Control $(\mathrm{n}=50)$ & 3.12 & 2.22 & 0.31 & 2.49 to 3.75 \\
Injunctive normative message $(\mathrm{n}=50)$ & 2.04 & 1.40 & 0.20 & 1.64 to 2.44 \\
Personal normative message $(\mathrm{n}=50)$ & 2.44 & 1.68 & 0.24 & 1.96 to 2.92 \\
Combined $(\mathrm{n}=50)$ & 1.86 & 1.34 & 0.19 & 1.48 to 2.24 \\
\hline
\end{tabular}

Note: Combined $=$ both injunctive and personal normative message provided in this condition.

An independent one-way ANOVA indicated that the number of plastic bags used differed significantly according to the normative messages, $F(3,196)=5.427, p<0.001$. Simple contrast analyses revealed that participants used significantly fewer free plastic bags in the injunctive normative message condition $(t(198)=3.15, p<0.01$, Cohen's $d=0.58)$ and in the combined injunctive and personal normative message condition $(t(198)=3.71, p<0.001$, Cohen's $d=0.69)$ than in the condition where there was only an environmental message, confirming Hypothesis 1 and part of Hypothesis 3. There was also a clear trend in that the personal normative message condition resulted in using fewer free plastic bags than in the control condition (Hypothesis 2). These effects were of medium strength $(t(198)=1.96, p=0.052$, Cohen's $d=0.35)$. The combined normative message did not significantly result in using fewer plastic bags than the personal $(t(197)=1.62, p=0.107$, Cohen's $d=0.38)$ or injunctive normative $(t(197)=-0.03, p=0.717$, Cohen's $d=0.13)$ message only, rejecting part of Hypothesis 3. We conducted the same analysis controlled for the size of the shopping. The results of the ANOVA remained largely the same $(F(3,195)=5.480, p<0.001)$, indicating that the influence of the normative messages on the difference in the use of free plastic bags was not dependent on size of the shopping.

\section{Discussion and Conclusions}

The current field study revealed that the use of persuasive normative messages in addition to standard environmental messages can encourage people to reduce their use of free plastic bags in a supermarket. As expected, customers used fewer free plastic bags when they received an injunctive normative message combined with the standard environmental message compared to the standard environmental message that merely emphasized the environmental benefits of reusing plastic bags only (Hypothesis 1). As suggested by the focus theory of normative conduct [21], emphasizing an injunctive norm in a message will make more salient what we would expect from someone in a specific situation, which accordingly promotes this behavior. These results are in line with earlier studies that focused on the influence of salient injunctive norms (in combination with salient descriptive norms) on other types of pro-environmental behaviors, such as removing petrified wood in nature reserves [26], littering [22,32], reusing towels [24], and conserving energy in households [28]. 
Thus, making an injunctive norm salient in a setting where a descriptive norm favors the undesired behavior, may be an effective way to promote a variety of environmental behaviors.

In our study, the majority of customers did not behave in line with the desired behavior (i.e., they used free plastic bags instead of reusing plastic bags), which could have resulted in customers perceiving a descriptive norm that was not in favor of the desired behavior (i.e., customers saw a majority of other customers using free plastic bags and not reusing plastic bags). Even though this undesired behavior was in place, using an injunctive normative message encouraged people to use fewer bags. This finding has important practical implications: a lot of pro-environmental behaviors include actions that are not done by the majority of people, but are regarded as morally correct. Thus, although it will be difficult to activate a descriptive normative message because the majority of people do not show the desired behavior as yet, most people hold an injunctive norm in favor of the desired (pro-environmental) behavior. Based on these findings, it would appear that changing pro-environmental behavior by focusing on injunctive normative messages is promising in encouraging behavior change. If the majority of people start performing the desired behavior, the descriptive norm will further support the injunctive norms until "stable" pro-environmental behaviors can be developed (cf., [24,26]).

Customers were less inclined to use free plastic bags when a message emphasized personal norms towards the environment by reusing bags compared to the environmental message-only condition lending support to Hypothesis 2. These results coincide with the suggestion that it is important to make personal norms salient, in a similar way as injunctive and descriptive norms (e.g., [21]), so as to encourage pro-environmental behavior. This assumption is also emphasized in the norm activation model [44], which specifically focuses on the influence of personal norms on pro-social (and pro-environmental) behavior and how these norms should be activated to guide pro-social and pro-environmental actions. Although personal norms have been regarded as important predictors for a diversity of pro-social and pro-environmental behaviors (e.g., [40-43]), none of these studies have focused on how we can manipulate the saliency of personal norms by normative message framing. This is one of the first studies that experimentally examined how personal normative messages could be used in encouraging pro-environmental behaviors in real-life settings. Our findings indicate that making personal norms salient may be an effective way to discourage the use of free plastic bags, and could therefore be used more often in interventions aimed to encourage pro-environmental behaviors.

We assume that the effect of our personal normative message could have been stronger had we changed the personal pronouns in our message. For example, Bolderdijk and colleagues [45,46] framed the personal normative message as: "Do you care about the environment? Check your tire pressure", which was significantly more effective in promoting pro-environmental behavior. In the present study, the personal normative message might have had a stronger effect if framed as: "Show that you care about the environment. Re-use your bags today!" or: "Do you care about the environment? Re-use your bags today". However, the supermarket management expressed the concern that such messages would be too personal and invasive for customers. As a result, we changed the framing of the personal normative message into: "We thank you for helping the environment by continuing to re-use your bags". Despite the fact our message could have been worded more strongly, this manipulation still resulted in the use of fewer free plastic bags with a similar or higher effect size (i.e., Cohen's $d=0.35$ ) than other behavior change intervention studies in the environmental domain. With a stronger personal normative message, the effectiveness of such messages on behavior change 
might increase even further, which is promising for future studies focusing on rendering personal norms salient. Future studies should systematically examine the effect of different types of personal normative messages on a variety of pro-environmental behaviors, and scrutinize to what extent various wordings in such messages may activate one's personal norm.

One important contribution of this study was that we were able to explore the combined effects of social and personal normative message framing. As expected and in line with studies that have investigated aligned normative injunctive and descriptive normative messages (i.e., [24,47]), a normative message emphasizing both one's injunctive and personal norms resulted in the lowest uptake of free plastic bags. Although the combined normative message showed the largest change in use of plastic bags, the difference was significant compared to the standard environmental message only and not compared to the injunctive or personal normative message only. The difference between the use of free plastic bags in the combined normative message and the personal normative message showed a medium effect size (Cohen's $d=0.39$ ), indicating a clear trend and promising results towards the facilitating effect of aligned injunctive and personal normative messages on reducing the intake of free plastic bags. Hence, our results provide partial support for Hypothesis 3 . It could be that the separate normative messages, especially the injunctive normative message, were already strong enough to optimally promote decreasing the use of free plastic bags; or, that a stronger personal normative message (see above) could have further strengthened the contribution of the combined message on the decrease of the use of free plastic bags. Based on the present results, we cannot exclude these explanations.

The present study did not include a control condition in which no message about reusing plastic bags could be provided, or, in which we also included a "neutral" environmental message (i.e., "Caring for the environment. Reuse your bags") on the signs used in our experiment. The lack of a control group makes it somewhat difficult to assess the contribution of the individual normative components of the messages. Confounding variables, such as the amount of words or the amount of signs used in the study could have contributed to the differences in plastic bag use instead of the message itself. As in other studies in this area of research (e.g., [25]), the field set-up of this study did not allow us to include a control group by removing existing signs from the setting. The results of this study suggest that the use of an extra normative message in addition to the existing environmental message in this supermarket was effective in reducing their use of free plastic bags. Future studies could replicate our results in more controlled lab studies in which similar words and signs for each of the conditions and a control group could be used, and, in which the effect of injunctive and personal normative messages on one's social and personal norms could be measured as well.

Keizer and colleagues [33] have shown that making norms in a specific context salient, by for example using normative messages, may activate one's normative goals towards acting in desirable and appropriate ways in a situational context as a whole; and, consequently, one will act pro-environmentally in other behavioral domains as well. Based on this assumption, we chose to measure the use of free plastic bags rather than re-using plastic bags, which was the focus in the normative messages and control condition. Our results seem to provide support for Keizer et al.'s assumption. That is, even though the normative messages were all focused on re-using plastic bags, we still found an effect of the normative messages on a slightly different type of pro-environmental behavior. Thus, instead of activating social and personal norms towards re-using bags only, our messages may have activated 
social and personal norms towards a diversity of pro-environmental behaviors (e.g., purchasing organic products, buying less meat), including the use of free plastic bags. It would be useful for future studies to measure a range of pro-environmental behaviors to examine this assumption in more detail.

The easiest way to decrease plastic bag use would be to not provide free plastic bags. Such a change in context will force a norm not to use free plastic bags without any messages. Unfortunately, such structural changes still seem to be difficult to implement in UK stores; most supermarkets throughout the UK are still offering free plastic bags to customers for their shopping [52]. Although supermarkets provide different (environmental) messages trying to encourage a reduction in the uptake of these free plastic bags, they still largely fail to decrease this uptake. The results of our study clearly indicate that some small changes in re-wording their messages by including normative information could result in customers acting more in line with their existing "pro-environmental" norms which eventually leads in the uptake of fewer free plastic bags. More specifically, our findings suggest that a specific behavioral focus of a message may be less relevant than the extent to which the message is normatively focused-hence, will activate normative goals. This flexibility towards using any behavioral focus as long as it is normatively framed makes it possible to tailor normative messages in such a way that it is still in line with the needs and opportunities of a specific shop. This will ultimately be an advantage in finance and convenience for supermarkets and beneficial in terms of environmental quality.

\section{Conflict of Interest}

The authors declare no conflict of interest.

\section{References and Notes}

1. McLaughlin, L. Paper, plastic or prada? Time 2007, 170, 49-51.

2. Waste \& Resources Action Programme. The "Choose to Reuse" Trial, Full Report 2005-2006. Available online: http://www.wrap.org.uk/retail_supply_chain/research_tools/research/report_ choose_to.html/ (accessed on 26 March 2011).

3. Williams, C. Battle of the bag. Newscientist 2004, 183, 30-33.

4. Steg, L.; Vlek, C. Encouraging pro-environmental behavior: An integrative review and research agenda. J. Environ. Psychol. 2009, 29, 309-317.

5. Stern, P.C. Toward a coherent theory of environmentally significant behavior. J. Soc. Issues 2000, 56, 407-424.

6. Lindenberg, S.; Steg, L. Normative, gain and hedonic goal frames guiding environmental behavior. J. Soc. Issues 2007, 63, 117-137.

7. Thøgersen, J. Recycling and morality-A critical review of the literature. Environ. Behav. 1996, 28, 536-558.

8. Black, J.S.; Stern, P.C.; Elworth, J.T. Personal and contextual influences on household energy adaptations. J. Appl. Psychol. 1985, 70, 3-21.

9. De Groot, J.I.M.; Steg, L. Morality and prosocial behavior: The role of awareness, responsibility and norms in the norm activation model. J. Soc. Psychol. 2009, 149, 425-449. 
10. Guagnano, G.A. Altruism and market-like behavior: An analysis of willingness to pay for recycled paper products. Popul. Environ. 2001, 22, 425-438.

11. Guagnano, G.A.; Dietz, T.; Stern, P.C. Willingness to pay: A test of the contribution model. Psychol. Sci. 1994, 5, 411-415.

12. Nordlund, A.M.; Garvill, J. Value structures behind pro-environmental behavior. Environ. Behav. 2002, 34, 740-756.

13. Tyler, T.R.; Orwin, R.; Schurer, L. Defensive denial and high cost prosocial behavior. Basic Appl. Soc. Psychol. 1982, 3, 267-281.

14. Lewis, D. Convention: A Philosophical Study; Harvard University Press: Cambridge, MA, USA, 1969.

15. Keizer, K.; Schultz, W. Social Norms and Pro-environmental Behavior. In Handbook of Environmental Psychology: An Introduction; Steg, L., van den Berg, A.E., de Groot, J.I.M., Eds.; Wiley-Blackwell: Oxford, UK, 2012; pp. 153-163.

16. De Groot, J.I.M.; Steg, L. General beliefs and the theory of planned behavior: The role of environmental concerns in the TPB. J. Appl. Soc. Psychol. 2007, 37, 1817-1836.

17. Haab, T.C.; McConnell, K.E. Social norms and illicit behavior: An evolutionary model of compliance. J. Environ. Manage. 2002, 66, 67-76.

18. Mosler, H.-J.; Blöchliger, O.R.; Inauen, J. Personal, social, and situational factors influencing the consumption of drinking water from arsenic-safe deep tubewells in Bangladesh. J. Environ. Manage. 2010, 91, 1316-1323.

19. Ramayah, T.; Lee, J.W.; Lim, S. Sustaining the environment through recycling: An empirical study. J. Environ. Manage. 2012, 102, 141-147.

20. Schade, J.; Schlag, B. Acceptability of urban transport pricing strategies. Transp. Res. Part F Traffic Psychol. Behav. 2003, 6, 45-61.

21. Cialdini, R.B.; Kallgren, C.A.; Reno, R.R. A focus theory of normative conduct: A theoretical refinement and reevaluation of the role of norms in human behavior. In Advances in Experimental Social Psychology; Zanna, M.P., Ed.; Academic Press: San Diego, CA, USA, 1991; Volume 24, pp. 201-234.

22. Cialdini, R.B.; Reno, R.R.; Kallgren, C.A. A focus theory of normative conduct: recycling the concept of norms to reduce littering in public places. J. Personal. Soc. Psychol. 1990, 58, 1015-1026.

23. Schultz, W. Changing behavior with normative feedback interventions: A field experiment on curbside recycling. Basic Appl. Soc. Psychol. 1998, 21, 25-38.

24. Schultz, W.; Khazian, A.; Zaleski, A. Using normative social influence to promote conservation among hotel guests. Soc. Influence 2008, 3, 4-23.

25. Goldstein, N.J.; Cialdini, R.B.; Griskevicius, V. A room with a viewpoint: using social norms to motivate environmental conservation in hotels. J. Consum. Res. 2008, 35, 472-482.

26. Cialdini, R.; Demaine, L.; Sagarin, B.; Barrett, D.; Rhoads, K.; Winter, P. Managing norms for persuasive impact. Soc. Influence 2006, 1, 3-15.

27. Nolan, J.M.; Schultz, P.W.; Cialdini, R.B.; Goldstein, N.J.; Griskevicius, V. Normative social influence is underdetected. Personal. Soc. Psychol. Bull. 2008, 34, 913-923. 
28. Schultz, W.; Nolan, J.; Cialdini, R.; Goldstein, N.; Griskevicius, V. The constructive, destructive, and reconstructive power of social norms. Psychol. Sci. 2007, 18, 429-434.

29. De Groot, J.I.M.; Schuitema, G. Making the unpopular popular: the influence of policy characteristics and normative information on the acceptability of environmental policies. Environ. Sci. Policy 2012, 15, 100-107.

30. Jacobson, R.P.; Mortensen, C.R.; Cialdini, R.B. Bodies obliged and unbound: differentiated response tendencies for injunctive and descriptive social norms. J. Personal. Soc. Psychol. 2011, 100, 433-448.

31. Cialdini, R.B. Crafting normative messages to protect the environment. Curr. Dir. Psychol. Sci. 2003, 12, 105-109.

32. Keizer, K.; Lindenberg, S.; Steg, L. The reversal effect of prohibition Signs. Group Process. Intergroup Relat. 2011, 14, 681-688.

33. Keizer, K.; Lindenberg, S.; Steg, L. The spreading of disorder. Science 2008, 322, 1681-1685.

34. Burger, J.M.; Bell, H.; Harvey, K.; Johnson, J.; Stewart, C.; Dorian, K.; Swedroe, M. Nutritious or delicious? The effect of descriptive norm information on food choice. J. Soc. Clin. Psychol. 2010, 29, 228-242.

35. Schultz, P.W.; Tabanico, J.J. Criminal beware: A social norms perspective on posting public warning signs. Criminology 2009, 47, 1201-1222.

36. Schwartz, S.H. Normative influences on altruism. In Advances in Experimental Social Psychology; Berkowitz, L., Ed.; Academic Press: New York, NY, USA, 1977; Volume 10, pp. 221-279.

37. Kallgren, C.A.; Reno, R.R.; Cialdini, R.B. A focus theory of normative conduct: When norms do and do not affect behavior. Personal. Soc. Psychol. Bull. 2000, 26, 1002-1012.

38. Harland, P.; Staats, H.; Wilke, H.A.M. Situational and personality factors as direct or personal norm mediated predictors of pro-environmental behavior: Questions derived from norm-activation theory. Basic Appl. Soc. Psychol. 2007, 29, 323-334.

39. Klöckner, C.; Blöbaum, A. A Comprehensive action determination model: Toward a broader understanding of ecological behavior using the example of travel mode choice. J. Environ. Psychol. 2010, 30, 574-586.

40. Arvola, A.; Vassallo, M.; Dean, M.; Lampila, P.; Saba, A.; Lahteenmaki, L.; Shepherd, R. Predicting intentions to purchase organic food: The role of affective and moral attitudes in the theory of planned behavior. Appetite 2008, 50, 443-454.

41. Dean, M.; Raats, M.M.; Shepherd, R. Moral concerns and consumer choice of fresh and processed organic foods. J. Appl. Soc. Psychol. 2008, 38, 2088-2107.

42. Thøgersen, J.; Ölander, F. The dynamic interaction of personal norms and environment-friendly buying behavior: A panel study. J. Appl. Soc. Psychol. 2006, 36, 1758-1780.

43. Jansson, J.; Marell, A.; Nordlund, A. Exploring consumer adoption of a high involvement eco-innovation using value-belief-norm theory. J. Consum. Behav. 2011, 10, 51-60.

44. Schwartz, S.H.; Howard, J.A. A Normative Decision Making Model of Altruism. In Altruism and Helping Behavior; Rushton, J.P., Sorrentino, R.M., Eds.; Erlbaum: Hillsdale, NJ, USA, 1981; pp. 89-211.

45. Bolderdijk, J.W. Buying People: The Persuasive Power of Money. Ph.D. Thesis, University of Groningen, Groningen, The Netherlands, 2010. 
46. Bolderdijk, J.W.; Steg, L.; Lehman, P.; Geller, S.; Postmes, T. Comparing the effectiveness of monetary versus moral motives in environmental campaigning. Nat. Clim. Change 2012, doi:10.1038/nclimate1767.

47. Smith, J.; Louis, W. Do as we say and as we do: The interplay of descriptive and injunctive group norms in the attitude-behavior relationship. Br. J. Soc. Psychol. 2008, 47, 647-666.

48. Thøgersen, J. Social norms and cooperation in real-life social dilemmas. J. Econ. Psychol. 2008, 29, 458-472.

49. Bicchieri, C. The grammar of society. In The Nature and Dynamics of Social Norms; Cambridge University Press: Cambridge, UK, 2006.

50. Thøgersen, J. Norms for environmentally responsible behavior: An extended taxonomy. J. Environ. Psychol. 2006, 26, 247-261.

51. Göckeritz, S.; Schultz, P.W.; Rendón, T.; Cialdini, R.B.; Goldstein, N.; Griskevicius, V. Descriptive normative beliefs and conservation behavior: The moderating role of personal involvement and injunctive normative beliefs. Eur. J. Soc. Psychol. 2010, 40, 514-523.

52. Boggan, S. Has YOUR Supermarket Banished the Bags? They Vowed to Clean up Their Act, But This Investigation Reveals What's Really Happening at the Checkout, 2011. Available online: http://www.dailymail.co.uk/news/article-2029023/Plastic-carrier-bags-Has-supermarket-banished -them.html/ (accessed on 17 May 2012).

(C) 2013 by the authors; licensee MDPI, Basel, Switzerland. This article is an open access article distributed under the terms and conditions of the Creative Commons Attribution license (http://creativecommons.org/licenses/by/3.0/). 